\begin{tabular}{|c|l|}
\hline Title & Monetary Policy Rules and the Effects of Fiscal Policy \\
\hline Author(s) & Kudoh, Noritaka; Nguyen, Hong Thang \\
\hline Citation & Discussion Paper, Series A, 220, 1-25 \\
\hline Issue Date & 2010-02 \\
\hline Doc URL & http://hdl.handle.net/2115/42609 \\
\hline Type & bulletin (article) \\
\hline File Information & DPA 220.pdf \\
\hline
\end{tabular}

Instructions for use 
Discussion Paper, Series A, No. 2010-220

\section{Monetary Policy Rules and the Effects of Fiscal Policy}

Noritaka Kudoh and Hong Thang Nguyen

February, 2010

Graduate School of Economics \& Business Administration Hokkaido University

Kita 9 Nishi 7, Kita-Ku, Sapporo 060-0809, JAPAN 


\title{
Monetary Policy Rules and the Effects of Fiscal Policy
}

\author{
Noritaka Kudoh* \\ Hong Thang Nguyen ${ }^{\dagger}$ \\ Hokkaido University \\ Hokkaido University
}

February 7, 2010

\begin{abstract}
We explore the implications of adopting a Taylor-type interest-rate rule in a simple monetary growth model in which budget deficits are financed partly by unbacked government debt. To ensure uniqueness of the steady-state equilibrium, monetary policy cannot be either too "active" or too "passive". The effects of fiscal policy depend crucially on whether monetary policy is active or passive, and are independent of the "tightness" of monetary policy.

JEL classification: E52, E62, H62, H63
\end{abstract}

Keywords: monetary policy rules, fiscal policy, overlapping generations

*Department of Economics, Kita 9 Nishi 7, Kita-ku, Sapporo 060-0809, JAPAN. Email: kudoh@econ.hokudai.ac.jp

${ }^{\dagger}$ Department of Economics, Kita 9 Nishi 7, Kita-ku, Sapporo 060-0809, JAPAN. Email: dr.thangnh@gmail.com 


\section{Introduction}

The past two decades have witnessed rapid growth in the literature on monetary policy rules. There are two important early contributions. Taylor (1993) suggested that US monetary policy can be best understood as an automatic policy rule relating the inflation rate and the output gap to the Federal Funds rate. This helps identify the activeness of a central bank through the estimate of the coefficients of the interest rate rule equation known as the Taylor rule. Leeper (1991) presented a theoretical inquiry into the relationship between the activeness of monetary policy and the uniqueness of equilibrium. Since Leeper (1991), determinacy of equilibrium has become one of the key criteria of a "good" fiscal-monetary policy.

Since the publication of Taylor (1993), many researchers have integrated a Taylor-type interestrate rule into a variety of dynamic general equilibrium monetary models to verify or challenge the so-called Taylor principle, according to which, for stability, the central bank must be "active", which means that it raises (cuts) the nominal interest rate by more than one percent if the inflation rate increases (decreases) by one percent. Using an infinite-horizon monetary model, Benhabib et al. (2001a) challenged this view by arguing that the relevance of the Taylor principle depends on the details about the way in which money is modeled. Carlstrom and Fuerst (2001) introduced capital accumulation to generalize the analysis of Benhabib et al. (2001a). Benhabib et al. (2001b) introduced the zero lower bound of the nominal interest rate into a Taylor rule to show the existence of a liquidity trap as an unintended alternative equilibrium.

This paper shares the spirit of Benhabib et al. (2001a, 2001b) in exploring the implications of adopting a Taylor-type interest-rate rule. Whereas the majority of the theoretical studies about the Taylor rule focus on the issue of determinacy, i.e., uniqueness of the rational expectations equilibrium, we focus on the properties of the steady-state equilibrium. In particular, we reconsider the effects of fiscal policy with special attention to the role of the automatic response of monetary policy implied by the Taylor rule.

This inquiry is not confined to academic interests. Since the financial crisis of 2007 and the recession that followed, there has been a resurgence of interest, among economists and policy-makers, 
in the effects of large-scale debt-financed government spending. ${ }^{1}$ Friedman (2006, p. 207) dubbed the sizable budget deficits in the US since 2001 "the return of large-scale fiscal irresponsibility". Only a few years later, what we observe around the globe is a massive increase in debt-financed government spending. Motivated by this observation, we study fiscal policy from the perspective of budget deficits and debt.

However, not all frameworks are appropriate for analyzing the complicated interaction between budget deficits and the real interest rate. According to the "Ricardian view", there should be no effect on the real interest rate, because a debt-financed increase in budget deficits induces the consumer to save more, offsetting the decrease in national saving caused by the deficits. Recent empirical studies (Engen and Hubbard, 2004; Gale and Orszag, 2004; Friedman, 2006; and Laubach, 2009) suggested a significant positive relationship between budget deficits and the real interest rate. This led Gale and Orszag (2004) to conclude, "the Ricardian view is not a good approximation to reality" (2004, p. 103). ${ }^{2}$

For the conduct of monetary policy, it is important to understand the way in which the real interest rate is affected by a change in the budget deficit, and by a change in monetary policy in response to a change in inflation that, in turn, results from that change in the budget deficit. As Bullard and Russell (1999) argued, departure from the world of Ricardian equivalence allows the government and the central bank to influence the real allocation through changes in the real interest rate.

In order to produce a departure from Ricardian equivalence, we adopt a monetary growth model with overlapping generations (OLG). One of the key features of the OLG economy is that

\footnotetext{
${ }^{1}$ Some of the questions concerning the effects of fiscal policy have been answered. For example, recent review articles such as Taylor (2009) and Feldstein (2009) suggested that the empirical evidence does not favor the use of countercyclical fiscal policy in stimulating consumption.

${ }^{2}$ Gale and Orszag (2004) considered three views, including the Ricardian view. According to the small open economy view, an increase in the deficit induces capital inflow that fully offsets the shortfall of national saving, so there should be little or no effect on real interest rates. Gale and Orszag's (2004) results are consistent with the conventional view, according to which capital inflow does not fully offset the fall in national saving, thereby raising real interest rates.
} 
it allows for equilibria with unbacked government debt. In a model where Ricardian equivalence holds, a debt-financed increase in budget deficits is simply a promise to increase tax in the future. However, with overlapping generations, the government can potentially raise revenue by rolling over the debt forever (i.e., the Samuelson case), because short-lived agents are willing to hold unbacked government debt as a useful means of saving. Friedman (2006, p. 220), among others, argued, "If the public does perceive part or all of the government's debt as an element of its overall wealth, so that higher debt means a lower capital stock [...], then implied changes in interest rates, and asset returns more generally, are an important part of the story." Thus, the OLG model provides a rich framework for analyzing the impact of the interaction between fiscal and monetary policies on economic activity through nominal and real interest rates.

In terms of the structure of the model, we follow Schreft and Smith $(1997,1998)$ and in particular Bhattacharya et al. (1997), hereafter BGHS. Schreft and Smith (1997) integrated the banking sector of the type developed by Diamond and Dybvig (1983) into a monetary growth model with overlapping generations. Schreft and Smith (1998) generalized Schreft and Smith's (1997) analysis to consider a variety of monetary policy instruments. However, both of these models assume that there is no fiscal deficit, thereby implicitly imposing a balanced-budget rule for the fiscal authority. ${ }^{3}$

BGHS extended Schreft and Smith $(1997,1998)$ to allow for a fiscal deficit. Although the BGHS model is substantially general, it has two important assumptions that limit the way macroeconomic policy is conducted. One is that the government spending (and the budget deficit) is procyclical in the sense that per capita government spending is proportional to the real wage rate. The other is that the central bank targets the ratio of government bonds and money.

In order to explore the implications for fiscal policy of adopting a Taylor rule, we follow BGHS and take a step further to relax the two assumptions BGHS made. First, we replace their monetary policy rule with a Taylor rule. Second, we introduce both government spending and taxation, and assume that the tax is proportional to the wage rate. This specification is motivated by the

\footnotetext{
${ }^{3}$ Adoption of a balanced budget is known to introduce nontrivial consequences. For the macroeconomic implications of adopting a balanced-budget rule, see Schmitt-Grohé and Uribe (1997, 2000).
} 
procyclical nature of tax revenue. Thus, constant government spending implies countercyclical budget deficits.

The model presented in this paper has money, government bonds, capital, taxation, government spending, and a Taylor rule. ${ }^{4}$ Although there are many endogenous variables to be determined, it turns out that the model is quite tractable. However, because the model is highly nonlinear, as in BGHS, we take a diagrammatic approach to characterizing equilibria. ${ }^{5}$ To highlight the roles of active and passive monetary policies, in our diagrammatic representation of the model, we isolate the locus that represents the automatic reactions of the central bank, whereas the other locus summarizes the private behaviors, the equilibrium conditions, and the budget constraints for the government and the central bank.

On the locus that represents the Taylor rule, the nominal interest rate is negatively related to the stock of capital and therefore output when monetary policy is active. Under an active monetary policy, the central bank reacts strongly to a change in the inflation rate, implying that the nominal interest rate changes more than the inflation rate. Thus, the Fisher equation implies that the nominal interest rate and the real interest rate are positively related. The opposite is true under a passive monetary policy. This difference has important implications for the number of steady-state equilibria as well as the effects of fiscal policy.

We obtain three important results. First, in any steady-state equilibrium, inflation promotes capital accumulation if and only if monetary policy is passive. Second, for uniqueness of a steadystate equilibrium, monetary policy cannot be either too active or too passive, because multiple equilibria can arise in either case. The elasticity of the nominal interest rate with respect to a change in inflation must be close to one. However, the output effect of fiscal policy is weaker as the elasticity gets closer to one. Third, when there is a unique steady state, fiscal policy unambiguously increases inflation. Under an active monetary policy, this translates into a higher nominal interest

\footnotetext{
${ }^{4}$ To simplify the exposition, we exclude the banking sector from our analysis to focus on the issue of fiscal-monetary policy interaction.

${ }^{5}$ Part of the reason for adopting a diagrammatic approach is that we encounter multiple steady-state equilibria. This requires a global analysis rather than a linearized local system.
} 
rate and lower capital and output. Under a passive monetary policy, this translates into a higher nominal interest rate, capital, and output.

When there are two steady-state equilibria, one of them has the same qualitative properties as the unique equilibrium. The other equilibrium has different qualitative properties. In the terminology of public finance, this alternative equilibrium is on the "wrong side" of the Laffer curve, on which the government should reduce inflation to finance an increased amount of deficit. This is because individuals substitute away from money as inflation goes up, thereby reducing the inflation tax base.

An additional contribution of this paper is that we clarify the relation of the results obtained from our model to those of the related literature. First, we consider the monetary policy instrument studied by Schreft and Smith (1998) and BGHS, in which the central bank conducts open market operations continuously to maintain the ratio of outstanding government bonds and money. Monetary policy is said to be "tight" when this ratio is high. We find that this type of policy necessarily implies that monetary policy is passive, and this is independent of how "tight" monetary policy is. In other words, the qualitative implications of fiscal policy are invariant to the tightness of monetary policy.

Second, we reconsider Friedman's (1969) recommendation to target the growth rate of a monetary aggregate. One of the major views against this prescription is that in practice, central bankers adopt an interest-rate rule because it is known to be difficult (or impossible) to perfectly control the stock of a monetary aggregate. ${ }^{6}$ Thus, we instead study a policy of targeting the speed of open market purchases. This policy should be much easier to implement in practice. We find that in any steady state, this policy exactly implements the same outcome as does Friedman's constant money growth rule. In addition, this policy is shown to be equivalent, in terms of its steady state implications, to targeting inflation in the strict sense. This implies that targeting the speed of open market operations is necessarily an active monetary policy.

The rest of the paper is organized as follows. Section 2 presents the model. Section 3 charac-

\footnotetext{
${ }^{6}$ Woodford (2003, p. 24) argued, "Monetary policy decisionmaking almost everywhere means a decision about the operating target for an overnight interest rate".
} 
terizes the steady state equilibria and presents some comparative statics. Section 4 discusses other monetary policy rules. Section 5 concludes. 


\section{The Model}

\subsection{Environment}

We consider an economy consisting of an infinite sequence of two-period-lived overlapping generations, an initial old generation, and an infinitely-lived government. Let $t=1,2, \ldots$ index time. At each date $t$, a new generation of a unit measure is born. Each agent is endowed with one unit of labor when young and is retired when old. In addition, the initial old agents are endowed with $K_{1}>0$ units of capital and $M_{0}>0$ units of fiat money.

There is a single final good produced using the Cobb-Douglas production function $Y_{t}=$ $A K_{t}^{\alpha} N_{t}^{1-\alpha}$ with $A \geq 1$ and $0<\alpha<1 / 2$, where $K_{t}$ denotes the capital input and $N_{t}$ denotes the labor input. Let $k_{t} \equiv K_{t} / N_{t}$ denote the capital-labor ratio. Then, the intensive production function is $f\left(k_{t}\right)=A k_{t}^{\alpha}$. It is easy to see that $f(0)=0, f^{\prime}>0>f^{\prime \prime}$, and the Inada conditions hold. The final good can either be consumed in the period it is produced, or stored to yield capital in the next period. For expositional reasons, capital is assumed to depreciate $100 \%$ between periods.

Factor markets are perfectly competitive. Thus, factors of production receive their marginal product. Let $r_{t}$ and $w_{t}$ denote the rental rate of capital and the real wage rate. Each young agent supplies his or her labor endowment inelastically in the labor market. Then, profit maximization requires $r_{t}=f^{\prime}\left(k_{t}\right)$ and $w_{t}=f\left(k_{t}\right)-k_{t} f^{\prime}\left(k_{t}\right) \equiv w\left(k_{t}\right)$, where $w^{\prime}(k)=-k f^{\prime \prime}(k)>0$. For the Cobb-Douglas specification, $r_{t}=\alpha A k_{t}^{\alpha-1}$ and $w\left(k_{t}\right)=(1-\alpha) A k_{t}^{\alpha}$.

\subsection{The Government and the Central Bank}

Following Azariadis and Lam (2009), we describe separately the budget constraints of the fiscal and monetary authorities. We let $G_{t}$ denote the government spending, $T_{t}$ denote the amount of tax revenue, $I_{t} \geq 1$ denote the gross nominal interest rate, and $B_{t}^{g}$ denote the amount of government bonds issued in period $t$. The fiscal authority's budget constraint is

$$
G_{t}+I_{t} B_{t-1}^{g}=T_{t}+B_{t}^{g}
$$


for $t \geq 2$ and $G_{1}=T_{1}+B_{1}^{g}$ for $t=1$. We assume that the government simply consumes $G_{t}$ and that $G_{t}$ does not affect the utility of any generation or the production process at any date. We divide (1) by $p_{t}$ and apply the Fisher equation $R_{t+1} \equiv I_{t+1} p_{t} / p_{t+1}$ to obtain

$$
g_{t}=\tau_{t}+b_{t}^{g}-R_{t} b_{t-1}^{g},
$$

where $g_{t}=G_{t} / p_{t}, \tau_{t}=T_{t} / p_{t}$, and $b_{t}^{g}=B_{t}^{g} / p_{t}$. Because bonds and capital are competing financial assets in this economy, the non-arbitrage condition requires the rates of return on these assets to be the same in equilibrium. Thus, $R_{t}=f^{\prime}\left(k_{t}\right)$.

If $B_{t}^{m}$ denotes the monetary authority's demand for government bonds, then the budget constraint for the central bank is

$$
B_{t}^{m}=I_{t} B_{t-1}^{m}+M_{t}-M_{t-1}
$$

for $t \geq 1$, where $B_{t}^{m}$ is the amount of government bonds purchased by the central bank through open market operations. ${ }^{7}$ Divide (3) by $p_{t}$ to obtain

$$
b_{t}^{m}=I_{t} \frac{p_{t-1}}{p_{t}} b_{t-1}^{m}+m_{t}-\frac{p_{t-1}}{p_{t}} m_{t-1}
$$

where $b_{t}^{m}=B_{t}^{m} / p_{t}$ and $m_{t}=M_{t} / p_{t}$. In what follows, we let $\Pi_{t} \equiv p_{t} / p_{t-1}$.

In this paper, we consider the following policy rules. The fiscal authority chooses the entire path for the real government spending. To simplify the analysis, we assume $g_{t}=g$ for all $t$. We assume that the tax is set to be proportional to the real wage rate:

$$
\tau_{t}=\theta w_{t}
$$

where $0 \leq \theta<1$ is an exogenous tax rate.

Following Leeper (1991), we assume that the central bank follows a Taylor-type (1993) feedback rule:

$$
I_{t}=I^{*}\left(\frac{\Pi_{t}}{\Pi^{*}}\right)^{\beta}
$$

\footnotetext{
${ }^{7}$ Kudoh (2007) considered a scenario in which the central bank injects money through "helicopter drops" rather than through open market operations.
} 
for $\beta>0$, and $I^{*}$ for $\beta=0$, where $I^{*}$ and $\Pi^{*}$ are the implicit targets for $I_{t}$ and $\Pi_{t}$. The level of $\beta$ is of paramount importance in the analysis. Linearizing (6) yields $I^{-1} d I=\beta \Pi^{-1} d \Pi$, or

$$
\frac{\Pi}{I} \frac{d I}{d \Pi}=\beta
$$

Thus, $\beta$ is the elasticity that captures the degree of aggressiveness of monetary policy. ${ }^{8}$

\subsection{Households}

In order to focus on agents' portfolio choice, we assume that all individuals save all their income. As a means of saving, agents may hold money and non-monetary assets. In order to motivate the demand for money as a liquid asset, we divide each period into two subperiods. The non-monetary assets, denoted by $Z_{t}$, are assumed to yield a gross nominal return of $I_{t+1} \geq 1$ in the next period. However, the non-monetary assets cannot be liquidated until the second subperiod. Money, whose nominal interest rate is zero, is assumed to be the only liquid asset in this economy. Thus, the only distinction between money and non-monetary assets is that non-monetary assets must be held a little longer (Martins, 1980; Kudoh, 2007).

We assume that each individual wishes to consume in both subperiods. Let $c_{1 t}$ and $c_{2 t}$ denote the consumption of the final good in the first and second subperiods, respectively, by an old agent born in period $t$. The individual's objective function is $\phi u\left(c_{1 t}\right)+(1-\phi) u\left(c_{2 t}\right)$, where $\phi$ captures the relative weight of utility between the two subperiods. Throughout, we use the following specification: $u(c)=[1-\rho]^{-1} c^{1-\rho}$ with $\rho \neq 1$ and $\rho>0$. Because the individual cannot liquidate non-monetary assets in the first subperiod, the agent faces a cash-in-advance constraint:

$$
p_{t+1} c_{1 t} \leq M_{t}
$$

The individual's budget constraint when young is

$$
M_{t}+Z_{t}=p_{t} w_{t}-T_{t},
$$

\footnotetext{
${ }^{8}$ The expression (6) does not have a term that relates the output gap to the nominal interest rate. It is important to note that in our flexible-price economy, the output gap is, by construction, zero (see, e.g., Woodford, 2003). Further, according to the estimates of Clarida, Galí, and Gertler (1998), the coefficient on the output gap is quite small for many central banks.
} 
where the consumer takes $H_{t}$ and $T_{t}$ as given. Similarly, the budget constraint when old is

$$
p_{t+1} c_{1 t}+p_{t+1} c_{2 t}=M_{t}+I_{t+1} Z_{t} .
$$

The cash-in-advance constraint binds as long as the (net) nominal interest rate is positive (i.e., $\left.I_{t}>1\right)$. Under the binding cash-in-advance constraint, (9) implies $p_{t+1} c_{2 t}=I_{t+1} Z_{t}=I_{t+1}\left[p_{t} w_{t}-\right.$ $\left.T_{t}-M_{t}\right]$. Thus, a young individual's maximization problem is:

$$
\max _{M_{t}}\left\{\phi \frac{\left[M_{t} / p_{t+1}\right]^{1-\rho}}{1-\rho}+(1-\phi) \frac{\left[\left(p_{t} w_{t}-T_{t}-M_{t}\right) I_{t+1} / p_{t+1}\right]^{1-\rho}}{1-\rho}\right\} .
$$

The first-order condition for this problem yields the following money demand function:

$$
\begin{aligned}
M_{t} & =\gamma\left(I_{t+1}\right)\left(p_{t} w_{t}-T_{t}\right) \\
\gamma\left(I_{t+1}\right) & \equiv\left[1+\left(\frac{1-\phi}{\phi}\right)^{1 / \rho} I_{t+1}^{1 / \rho-1}\right]^{-1}
\end{aligned}
$$

It is easy to establish that $\gamma^{\prime}(I)<0$ holds for $\rho \in(0,1), \lim _{I \rightarrow \infty} \gamma(I)=0$ and $\lim _{I \rightarrow 0} \gamma(I)=1$ hold for $\rho \in(0,1)$, and $\gamma(1)=\left[1+((1-\phi) / \phi)^{1 / \rho}\right]^{-1}$. The value of $\rho$ captures the strength of the income effect of a change in $I$. Throughout, we focus on the case in which $\rho \in(0,1)$ so that the income effect is relatively weak.

In Schreft and Smith $(1997,1998)$ and BGHS, markets are spatially separated, communication across the markets is limited, and their "relocation shock" is similar to the liquidity preference shock of Diamond and Dybvig (1983). In such an environment, financial intermediation arises to provide perfect risk sharing through demand deposit contracts, and the deposit demand function is known to have the same form as (11). For brevity of exposition, we do not introduce the banking sector. $^{9}$

\section{Equilibrium}

\subsection{Characterization}

A monetary equilibrium is defined by a set of sequences for allocations $\left\{m_{t}, b_{t}, k_{t}\right\}$ and relative prices $\left\{R_{t}, \Pi_{t}\right\}$, and initial conditions $K_{1}>0, M_{0}>0$, and $B_{0}=0$ such that: each household

\footnotetext{
${ }^{9}$ BGHS studied the reserve requirement the banking sector faces.
} 
maximizes utility; the factor markets clear; the asset markets clear; the fiscal authority's budget constraint is satisfied; the monetary authority's budget constraint is satisfied; fiscal policy specifies sequences for $g_{t}$ and $\tau_{t}$; and monetary policy specifies a sequence for $I_{t}$.

The equilibrium conditions for the asset markets are as follows. First, dividing (11) by $p_{t}$ yields

$$
m_{t}=(1-\theta) \gamma\left(I_{t+1}\right) w\left(k_{t}\right)
$$

which turns out to be the market clearing condition for money. The bond market equilibrium requires $B_{t}+B_{t}^{m}=B_{t}^{g}$, where $B_{t}$ is the bond holdings by the household. In real terms, we have

$$
b_{t}+b_{t}^{m}=b_{t}^{g}
$$

The capital market equilibrium requires $Z_{t}=B_{t}+p_{t} K_{t+1}$. Dividing it by $p_{t}$ yields

$$
b_{t}+k_{t+1}=(1-\theta)\left[1-\gamma\left(I_{t+1}\right)\right] w\left(k_{t}\right) .
$$

We substitute the government budget constraint (2) and the central bank's budget constraint (4) into (14) to obtain the consolidated government budget constraint:

$$
g-\theta w\left(k_{t}\right)=b_{t}-R_{t} b_{t-1}+m_{t}-\frac{p_{t-1}}{p_{t}} m_{t-1}
$$

\subsection{Steady-state Equilibria}

Throughout the paper, we focus on the steady-state equilibria, in which all real variables are invariant over time. It is easy to show that the monetary policy rule (6), the Fisher equation, and the arbitrage condition between bonds and capital $\left(R_{t}=f^{\prime}\left(k_{t}\right)\right)$ reduce to

$$
I=\left(\frac{I^{* 1 / \beta}}{\alpha A \Pi^{*}}\right)^{\frac{\beta}{1-\beta}} k^{\frac{\beta(1-\alpha)}{1-\beta}} \equiv i(k) .
$$

Similarly, we substitute the market clearing conditions for money (13) and capital (15) into the consolidated government budget constraint (16) to obtain

$$
1-\gamma(I)+\frac{\gamma(I)}{I}=\frac{f(k)-k-g}{(1-\theta) f^{\prime}(k) w(k)},
$$


or

$$
\mu(I)=\frac{\left[A k^{\alpha}-k-g\right] k^{1-2 \alpha}}{\alpha(1-\alpha)(1-\theta) A^{2}} \equiv \eta(k),
$$

where $\mu(I) \equiv 1-\gamma(I)+\gamma(I) / I$. Thus, a steady state equilibrium is determined by a solution to the system of equations (17) and (18). It follows from the properties of the function $\gamma(I)$ that $\mu(1)=1$, and for $\rho \in(0,1), \lim _{I \rightarrow 0} \mu(I)=\infty$ and $\lim _{I \rightarrow \infty} \mu(I)=1$. Thus suggests that the function $\mu(\cdot)$ is generally $\mathrm{U}$-shaped. However, because $I$ is the (gross) nominal interest rate, the value of $I$ we study can be limited to a range that is close to one. In addition, we exclude the scenario of a negative nominal interest rate $(I<1)$ from our analysis.

Lemma $1 \mu^{\prime}(I)<0$ holds for $I \in[1,1 /(1-\rho)]$.

Proof. Since $\mu(I) \equiv 1-\gamma(I)+\gamma(I) / I>0$, it is easy to show that

$$
\mu^{\prime}(I)=-\frac{I-1}{I} \frac{\gamma(I)}{I}\left[\frac{1}{I-1}+\frac{I \gamma^{\prime}(I)}{\gamma(I)}\right]=-\frac{I-1}{I} \frac{\gamma(I)}{I}\left[\frac{1}{I-1}-\frac{1-\rho}{\rho}[1-\gamma(I)]\right] .
$$

Since we maintain the assumption $0<\rho<1$, it is evident that $(1-\rho) I \leq 1$ implies $(I-1)^{-1} \geq(1-$ $\rho) / \rho$ and that $\gamma(I)>0$ for $I<1 /(1-\rho)$. Note that $\gamma(I)>0$ implies $(1-\rho) / \rho>[1-\gamma(I)](1-\rho) / \rho$ for any $I \in[1,1 /(1-\rho)]$. It follows that $(I-1)^{-1}-(1-\rho) / \rho \geq 0$ implies $(I-1)^{-1}-[1-\gamma(I)](1-\rho) / \rho>0$. Thus, (19) implies that $\mu^{\prime}(I)<0$ holds for $I \in[1,1 /(1-\rho)]$.

Lemma 1 helps identify the region of $I$ in which the function $\mu(\cdot)$ is monotonic and therefore invertible. Throughout this section, we limit our attention to the region $I \in[1,1 /(1-\rho)]$. It follows from the expression (18) that

$$
I=\mu^{-1}(\eta(k)) \equiv \Omega(k)
$$

It is now evident that the steady-state equilibria are completely characterized diagrammatically by the intersections of the two loci defined by (17) and (20). To proceed, we need to study the shapes of the two loci.

We start with the first locus, (17). It is easy to obtain

$$
i^{\prime}(k)=\left(\frac{I^{* 1 / \beta}}{\alpha A \Pi^{*}}\right)^{\frac{\beta}{1-\beta}} \frac{\beta(1-\alpha)}{1-\beta} k^{\frac{\beta(1-\alpha)}{1-\beta}-1},
$$


from which it is easy to establish that the (17)-locus is downward sloping under an active monetary policy $(\beta>1)$ and is upward sloping under a passive monetary policy $(\beta<1)$.

The intuition is as follows. Under an active monetary policy, the central bank reacts strongly to a change in the inflation rate, implying that the nominal interest rate changes more than the inflation rate. Thus, the Fisher equation $(R=I / \Pi)$ implies that the nominal interest rate and the real interest rate are positively related. Therefore, the nominal interest rate and the stock of capital are negatively related along the (17)-locus under an active monetary policy. Because the nominal interest rate changes less than the inflation rate under a passive monetary policy, the nominal interest rate and the stock of capital are positively related along the (17)-locus.

We now proceed to studying the configuration of the (20)-locus. To do so we first need to study the properties of the function $\eta(k)$. It is easy to verify that, because $\alpha<1 / 2$, the equation $\eta(k)=0$ has three roots: $k=0$ and the roots of $A k^{\alpha}-k-g=0$. In addition, we note that $\eta(0)=0$ and $\lim _{k \rightarrow} \eta(k)=-\infty$. From the definition of $\eta(k)$, it is easy to obtain

$$
\eta^{\prime}(k)=\frac{A k^{\alpha}-2 k-\frac{1-2 \alpha}{1-\alpha} g}{\alpha(1-\theta) A^{2} k^{2 \alpha}} .
$$

It is easy to verify that $\lim _{k \rightarrow 0} \eta^{\prime}(k)=-\infty$ and $\lim _{k \rightarrow \infty} \eta^{\prime}(k)=-\infty$. Let $\underline{k}^{\prime}$ and $\bar{k}^{\prime}\left(\underline{k}^{\prime}<\bar{k}^{\prime}\right)$ denote the two distinct solutions to the numerator of $(21)$. Then, $\eta^{\prime}(k)>0$ holds for $k \in\left(\underline{k}^{\prime}, \bar{k}^{\prime}\right)$. The level of $\eta(k)$ reaches its minimum at $k=\underline{k}^{\prime}$ and its maximum at $k=\bar{k}^{\prime}$, as shown in Figure 1. ${ }^{10}$ Since we limit our attention to $I \in[1,1 /(1-\rho)]$, this will limit the region of $k$ as well. $I \in[1,1 /(1-\rho)]$ implies that $\mu(I) \in[\mu(1 /(1-\rho)), \mu(1)]$. Let $\underline{k}$ and $\bar{k}$ denote the two distinct solutions to $\mu(1 /(1-\rho))=\eta(k)$. It is then easy to verify that $\eta(k)>0$ for any $k \in[\underline{k}, \bar{k}]$. Further, it is evident that an increase in $g$ shifts the $\eta(k)$-locus downward.

We now study the (20)-locus. It is easy to verify that $\Omega^{\prime}(k)=\eta^{\prime}(k) / \mu^{\prime}(I)$ and $\Omega^{\prime \prime}(k)=$ $\eta^{\prime \prime}(k) / \mu^{\prime}(I)$. Thus, the configuration of $\Omega(k)$ can be deduced from that of $\eta(k)$. Noticing $\mu^{\prime}(I)<0$ for $I \in[1,1 /(1-\rho)]$, it is straightforward to obtain the configuration of $\Omega(k)$, which is depicted in

\footnotetext{
${ }^{10} \mathrm{An}$ intuitive way of verifying the configuration of $\eta(k)$ is to start with the configuration of $A k^{\alpha}-k$. The configuration of $A k^{\alpha}-k-g$ is obtained by a parallel downward shift of this diagram. Finally, multiplying the diagram by $k^{1-2 \alpha}$ gives the diagram shown in Figure 1.
} 
Figure 2. It is easy to verify that an increase in $g$ shifts the locus upward. It is important to note that part of the (20)-locus can be below $I=1$. However, we can safely exclude such a scenario by considering the case where $g$ is sufficiently high.

Having established the configurations of the two loci, (17) and (20), we are now in the position to find the steady-state equilibria.

Proposition 2 There is a unique steady state equilibrium if $k^{*}$ satisfies $\underline{k}<k^{*}<\bar{k}$, where

$$
k^{*} \equiv\left(\frac{1}{1-\rho}\right)^{\frac{1-\beta}{\beta(1-\alpha)}}\left(\frac{\alpha A \Pi^{*}}{I^{* 1 / \beta}}\right)^{\frac{1}{1-\alpha}} .
$$

If $k^{*}$ satisfies $k^{*}<\underline{k}$ or $\bar{k}<k^{*}$, then there are at most two steady state equilibria.

We construct a proof of proposition 2 in what follows using diagrams. Since we limit our analysis to $I \in[1,1 /(1-\rho)]$, we define $\tilde{k}$ and $k^{*}$ to be the solutions to $i(k)=1$ and $i(k)=1 /(1-\rho)$, respectively. In particular, $\tilde{k} \equiv\left(\alpha A \Pi^{*} / I^{* 1 / \beta}\right)^{1 /(1-\alpha)}$. Figure 3 depicts a case in which $k^{*}$ satisfies $\underline{k}<k^{*}<\bar{k}$. Since the function $i(k)$ is monotonic for any $\beta \geq 0$, it is evident from the figure that the steady state is uniquely determined.

Figure 4 describes a case in which $k^{*}$ satisfies $k^{*}<\underline{k}$. For existence of a steady state, it must be the case that $k^{*}<\tilde{k}$. To see this, consider

$$
\tilde{k}-k^{*}=\left[1-\left(\frac{1}{1-\rho}\right)^{\frac{1-\beta}{\beta(1-\alpha)}}\right]\left(\frac{\alpha A \Pi^{*}}{I^{* 1 / \beta}}\right)^{\frac{1}{1-\alpha}} .
$$

Since $0<\rho<1$ and $0<\alpha<1 / 2$, it is easy to verify that $\tilde{k}>k^{*}$ if and only if $\beta>1$. Further, (22) suggests that the case with $k^{*}<\underline{k}$ arises when monetary policy is sufficiently active. It is important to note that, in this case, the existence of a steady state is not guaranteed. In fact, there may be no steady state equilibrium if $g$ is sufficiently large. Similarly, Figure 5 describes a case in which $k^{*}$ satisfies $\bar{k}<k^{*}$, which occurs when monetary policy is significantly passive.

\subsection{The Effects of Fiscal Policy}

We now consider the effects of fiscal policy. 
Proposition 3 Suppose $k^{*}$ satisfies $\underline{k}<k^{*}<\bar{k}$. If monetary policy is active, then an increase in $g$ reduces $k$ and increases $I$ and $\Pi$. If monetary policy is passive, then it increases $k, I$, and $\Pi$.

These results are illustrated in Figure 6 . An upward shift in the $\Omega(k)$-locus causes the economy to move along the $i(k)$-locus. Since the locus is upward sloping under an active monetary policy, the economy moves from point A to point B. The intuition is as follows. An increase in government spending requires an increase in either the direct tax revenue, the seigniorage, or the revenue from bonds. The monetary policy rule (6) and the Fisher equation imply $R=I^{*}\left(\Pi^{*}\right)^{-\beta} \Pi^{\beta-1}$, so an increase in inflation reduces capital accumulation if and only if monetary policy is active. Thus, under an active monetary policy, an increase in the government's need for revenue increases the inflation rate, which increases both the nominal and the real interest rates. In other words, when the central bank is a tough inflation fighter, an increase in government spending will result in higher nominal and real interest rates, reducing capital and output.

When monetary policy is passive, higher inflation reduces the real interest rate and increases capital and output. In this case, an increase in government spending increases both the inflation rate and the nominal interest rate. The overall effect on the real interest rate is negative, so the stock of capital and output increase. In Figure 6, the economy moves from point A' to point B'.

The effects of fiscal policy when there are two steady state equilibria are more subtle. Let $k_{L}$ and $k_{H}\left(k_{L}<k_{H}\right)$ denote the two distinct steady state equilibria. Then, we establish the following. Proposition 4 Suppose that monetary policy is active and $k^{*}$ satisfies $k^{*}<\underline{k}$. An increase in $g$ increases $k$ and decreases $I$ and $\Pi$ at $k_{L}$. It decreases $k$ and increases $I$ and $\Pi$ at $k_{H}$.

We first consider the steady state at $k_{H}$. The effect is depicted by the movement from point $\mathrm{A}$ to point B in Figure 7. An increase in government spending increases the need for revenue. At this steady state, an increase in inflation can raise revenue. Thus, the rate of inflation increases and the central bank reacts strongly by raising the nominal interest rate. Under an active monetary policy, an increase in the nominal interest rate dominates the increase in inflation, so the real interest rate goes up as well. This reduces capital and output. What happens to this steady state exactly corresponds to the case of the unique steady-state equilibrium shown in Figure 6. 
The effect of fiscal policy at $k_{L}$ is shown by the movement from point $\mathrm{C}$ to point $\mathrm{D}$ in Figure 7. This steady state is on the "wrong side" of the inflation Laffer curve, in the sense that the rate of inflation is so high that a further increase in the rate of inflation will shrink the inflation tax base and thereby reduce revenue. Thus, at this steady state, an increase in government spending causes the inflation rate to decrease. The central bank will aggressively cut the nominal interest rate, and as a result, the real interest rate will go down, thereby increasing capital and output.

Proposition 5 Suppose that monetary policy is passive and $k^{*}$ satisfies $\bar{k}<k^{*}$. An increase in $g$ increases $k, I$, and $\Pi$ at $k_{L}$. It decreases $k, I$, and $\Pi$ at $k_{H}$.

When monetary policy is passive, the steady state at $k_{L}$ corresponds to the unique steady-state equilibrium described in Figure 6, and the steady state at $k_{H}$ corresponds to the "wrong side" of the inflation Laffer curve. Consider the movement from point $\mathrm{A}^{\prime}$ to point $\mathrm{B}$ ' in Figure 8. An increase in government spending increases the need for revenue. At $k_{L}$, the rate of inflation must rise to finance an increased deficit. The central bank react by raising the nominal interest rate slightly, so the real interest rate decreases. As a result, capital and output increase. At the other steady state, the rate of inflation is already high, so the inflation rate must decrease to finance an increased deficit. A passive monetary policy implies that there will not be a large cut in the nominal interest rate, so the real interest rate increases, and capital and output decrease.

\subsection{Discussion}

It is interesting to consider the case in which $\rho$ is small so that $\mu(I)$ is increasing. In particular, we assume $\rho$ is significantly small such that $\rho /(1-\rho)<(I-1)[1-\gamma(I)]$ is satisfied, under which $\mu^{\prime}(I)>0$ holds. In this case, the substitution effect of a change in the nominal interest rate is so strong that a small reduction in the nominal interest rate increases the demand for money significantly. This case is similar to the economy on the "wrong side" of the Laffer curve, because an increase in inflation reduces the inflation tax base significantly. With such a money demand function, even a significant change in the stock of money cannot influence the nominal interest rate, and this is the classic case of the "liquidity trap" in the old literature. 
Interestingly, the effects of fiscal policy are reversed. Figure 9 depicts the effects of an increase in government spending under an active monetary policy. When money demand is elastic, an increase in inflation induces households to substitute money for bonds and capital. Thus, higher inflation reduces the government's revenue. As a result, an increase in government spending causes a decrease in the inflation rate. The central bank reacts strongly by cutting the nominal interest rate, reducing the real interest rate as a result. This will increase capital and output. The effect is described as the movement from point A' to point B'.

If there are two distinct steady-state equilibria, there is another type of steady state, at which the inflation rate is so low that a further decrease in inflation cannot expand the inflation tax base. As shown by the movement from point $\mathrm{C}$ to point $\mathrm{D}$, an increase in government spending increases the rate of inflation. The central bank raises the nominal interest rate significantly to cause an increase in the real interest rate.

Under a passive monetary policy, an increase in government spending induces the inflation rate to decrease (to expand the inflation tax base) to finance a larger deficit. The central bank reacts by cutting the nominal interest rate. Overall, the real interest rate goes up because monetary policy is passive. This is depicted by the movement from point A' to point B' in Figure 10. If there are two distinct steady-state equilibria, there is another steady state, in which an increase in government spending increases the rate of inflation. The central bank reacts weakly by raising the nominal interest rate. Overall, the real interest rate decreases.

Finally, it is interesting to consider the case of a strong income effect. In particular, let us consider the case in which $\rho>1$, in which case we have $\gamma^{\prime}(I)>0$ (Schreft and Smith, 1998). In other words, money demand is increasing in the nominal interest rate. It is easy to verify from (19) that $\mu^{\prime}(I)<0$ holds for any $I>1$ if $\gamma^{\prime}(I)>0$. This implies that the results in Section 3 are maintained. In other words, except for the case of elastic money demand, our results concerning the effects of fiscal policy are fairly general. 


\section{Alternative Methods of Conducting Monetary Policy}

\subsection{Constant Bonds-Money Ratio}

In this section, we clarify the relationship between the Taylor rule considered in the preceding sections and other methods of conducting monetary policy. We first discuss the monetary policy studied by Schreft and Smith (1998) and BGHS, which is given by

$$
\frac{B_{t}}{M_{t}}=\lambda
$$

where $\lambda>0$. A conventional interpretation of this type of monetary policy is that the central bank continuously conducts open market operations to keep the ratio of bonds and money constant. Monetary policy is said to be "tight" if $\lambda$ is high, and "loose" if it is low. In practice, this type of policy rule is easier to implement than is the constant money growth rule, because (23) requires the central bank simply to match the outstanding bonds to the monetary base. No control of base money is required.

It is easy to verify that (23) implies $b_{t}=\lambda m_{t}$. Combining this equation and the market clearing conditions for money (13) and capital (15) yields

$$
1-(1+\lambda) \gamma(I)=\frac{k^{1-\alpha}}{(1-\theta)(1-\alpha) A} .
$$

Thus, the steady-state equilibria are determined by (24) and (20). It is easy to verify that (24) implies a positive relationship between $I$ and $k$. Thus, in terms of the relationship between $I$ and $k$, this type of monetary policy corresponds to a passive monetary policy for any $\lambda>0$. To determine whether this policy is active or not, we need to derive the elasticity of the nominal interest rate with respect to the rate of inflation.

Lemma 6 Along the (24)-locus, $\frac{\Pi}{I} \frac{d I}{d \Pi}<1$ holds for any $\lambda>0$.

Proof. Totally differentiate the Fisher equation, $I=\Pi f^{\prime}(k)$ to obtain $d I=f^{\prime}(k) d \Pi+$ $\Pi f^{\prime \prime}(k) d k$. Similarly, totally differentiate $(24)$ to obtain $-(1-\theta) A(1+\lambda) \gamma^{\prime}(I) d I=k^{-\alpha} d k$. Combining these expressions yields

$$
\frac{\Pi}{I} \frac{d I}{d \Pi}=\frac{1}{1-(1-\alpha) A k^{\alpha-1}(1-\theta)(1+\lambda) I \gamma^{\prime}(I)}<1 .
$$


This result is revealing. Monetary policy that targets the ratio of bonds and money amounts to a passive monetary policy, in the sense that the central bank raises (cuts) the nominal interest rate less than one percent in response to a one percent increase (decrease) in the rate of inflation, and this fact is invariant to the degree of tightness. A new insight is that, because the effects of fiscal policy are determined by whether monetary policy is active or passive, the effects are independent of the tightness of monetary policy. Thus, for the effects of fiscal policy, it does not matter how tight or loose a monetary policy becomes. However, tightness may affect the number of steady-state equilibria. From (25), $\frac{\Pi}{I} \frac{d I}{d \Pi} \rightarrow 0$ as $\lambda \rightarrow \infty$. This suggests that a significantly tight monetary policy may cause multiple equilibria.

\subsection{Constant Growth of Open Market Purchases}

In his famous article, Friedman (1968, p. 16) argued that the monetary authority should adopt "the policy of achieving a steady rate of growth in a specified monetary total." However, many of the recent studies appear to have abandoned Friedman's constant money growth rule in their analyses because an interest-rate policy is more practical (Woodford, 2003).

Motivated by this debate, in this section, we briefly discuss a possible alternative to a constant money growth rule. In particular, we consider the following monetary policy rule.

$$
B_{t}^{m}=\sigma B_{t-1}^{m}
$$

where $\sigma>0$ is a parameter chosen by the central bank. According to (26), the central bank targets the quantity of government bonds held by the central bank. In particular, the rate of growth of the quantity purchased is held constant. Even if direct control of the stock money is difficult in practice, policy rule (26) should be easy to implement.

Lemma 7 In any steady state, the following three monetary policy rules are equivalent to each other: (i) $B_{t}^{m}=\sigma B_{t-1}^{m}$, (ii) $M_{t}=\sigma M_{t-1}$, and (iii) $\Pi_{t}=\sigma$.

Proof. In real terms, $B_{t}^{m}=\sigma B_{t-1}^{m}$ is $b_{t}^{m}=\left(\sigma / \Pi_{t}\right) b_{t-1}^{m}$, and $M_{t}=\sigma M_{t-1}$ is $m_{t}=\left(\sigma / \Pi_{t}\right) m_{t-1}$. 
Thus, at a steady state, each of these equations implies $\Pi=\sigma$. This is equivalent to the steady state of policy (iii).

Thus, at any steady state, the policy of targeting the speed of open market operations exactly implements the same outcome as does Friedman's (1968) constant money growth rule. In addition, this policy is equivalent to the targeting of inflation in the strict sense. Under any of the policies above, the steady-state equilibria are determined by $I=\sigma f^{\prime}(k)$ and (20).

This implies that targeting the speed of open market operations is necessarily an active mon-

etary policy. To see this, we rewrite (6) as $\Pi_{t}=\Pi^{*}\left(I_{t} / I^{*}\right)^{\frac{1}{\beta}}$, from which it is easy to show that $\Pi_{t}=\Pi^{*}(=\sigma)$ holds in the limit as $\beta \rightarrow \infty$. Thus, strict inflation targeting is an extremely active monetary policy. This suggests that this policy may induce multiple equilibria. It is evident that as $\beta \rightarrow \infty, k^{*} \rightarrow[(1-\rho) \alpha A \sigma]^{1 /(1-\alpha)}$. There are two steady-state equilibria if $[(1-\rho) \alpha A \sigma]^{1 /(1-\alpha)}<\underline{k}$. Thus, to prevent multiple equilibria, the speed of open market operations $\sigma$ must be high enough.

\section{Conclusion}

In this paper, we avoided making any comment on the dynamic properties of the model. Stability analyses have proven to be useful when there are multiple steady-state equilibria. However, there are various results in the literature, which indicates that the stability results are significantly influenced by the choice of timing regarding the Taylor rule (Benhabib et al., 2001a; Carlstrom and Fuerst, 2001). Thus, we simply point out that the same would be true for our model. Studying the dynamic properties of the model is nonetheless important for future research.

Although we focused on the steady-state behaviors of the model, we found several interesting results. First, for uniqueness of equilibrium, monetary policy cannot be either too active or too passive. Second, we clarified the two seemingly related concepts, tightness and activeness. Activeness of monetary policy has a profound impact on the effects of fiscal policy, whereas tightness does not. Third, a policy of targeting the speed of open market operations can implement Friedman's (1968) constant money growth rule, but this policy implies an extremely active monetary policy, which can result in multiple equilibria. 
An important limitation of our analysis is that we ignore the role played by financial intermediaries in propagating the effects of fiscal and monetary policies. This was addressed by Schreft and Smith $(1997,1998)$ and BGHS. An important future issue is to consider a variety of policies that are designed to influence the banking sector to clarify its relationship with the conventional monetary policy tools. 


\section{References}

[1] Azariadis, Costas, and Raphael W. K. Lam. "Efficient Inflation Targets for Distorted Dynamic Economies." in D. E. Altig and E. Nosal (editors) Monetary Policy in Low-Inflation Economies, Cambridge University Press, New York, 2009.

[2] Benhabib, Jess, Stephanie Schmitt-Grohé, and Martín Uribe. "Monetary Policy and Multiple Equilibria." American Economic Review 91 (2001a) 167-186.

[3] Benhabib, Jess, Stephanie Schmitt-Grohé, and Martín Uribe. "The Perils of Taylor Rules." Journal of Economic Theory 96 (2001b) 40-69.

[4] Bhattacharya, Joydeep, Mark G. Guzmen, Elisabeth Huybens, and Bruce D. Smith. "Monetary, Fiscal, and Reserve Requirement Policy in a Simple Monetary Growth Model." International Economic Review 38 (1997) 321-350.

[5] Bullard, James, and Steven Russell. "An Empirically Plausible Model of Low Real Interest Rates and Unbacked Government Debt." Journal of Monetary Economics 44 (1999) 477-508.

[6] Carlstrom, Charles T., and Timothy S. Fuerst. "Real Indeterminacy in Monetary Models with Nominal Interest Rate Distortions." Review of Economic Dynamics 4 (2001) 767-789.

[7] Clarida, Richard, Jordi Galí, and Mark Gertler. "Monetary Policy Rules in Practice: Some International Evidence," European Economic Review 42 (1998) 1033-1067.

[8] Diamond, Douglas W., and Philip H. Dybvig. "Bank Runs, Deposit Insurance, and Liquidity." Journal of Political Economy 91 (1983) 401-419.

[9] Engen, Eric M., and R. Glenn Hubbard. "Federal Government Debt and Interest Rates." in, Mark Gertler and Kenneth Rogoff (editors), NBER Macroeconomics Annual 2004, MIT Press, Cambridge, Massachusetts, 2004.

[10] Feldstein, Martin. "Rethinking the Role of Fiscal Policy." American Economic Review 99 (2009) 556-559. 
[11] Friedman, Benjamin, M. "Deficits and Debt in the Short and Long Run." in, Richard W. Kopcke, Geofferey M. B. Tootell, and Robert K. Triest (Editors) The Macroeconomics of Fiscal Policy, MIT Press, Cambridge, Massachusetts, 2006.

[12] Friedman, Milton. "The Role of Monetary Policy." American Economic Review 58 (1968) $1-17$.

[13] Gale, William G., and Peter R. Orszag. "Budget Deficits, National Saving, and Interest Rates." Brookings Papers on Economic Activity 2:2004 (2004) 101-187.

[14] Kudoh, Noritaka. "Low Nominal Interest Rates: A Public Finance Perspective," International Journal of Central Banking, 3 (2007) 61-93.

[15] Laubach, Thomas. "New Evidence on the Interest Rate Effects of Budget Deficits and Debt." Journal of the European Economic Association 7 (2009) 858-885.

[16] Leeper, Eric M. "Equilibria under 'Active' and 'Passive' Monetary and Fiscal Policies," Journal of Monetary Economics 27 (1991) 129-147.

[17] Martins, Marco A. C. "A Nominal Theory of the Nominal Rate of Interest and the Price Level." Journal of Political Economy 88 (1980) 174-185.

[18] Schmitt-Grohé, Stephanie, and Martín Uribe. "Balanced-Budget Rules, Distortionary Taxes, and Aggregate Instability." Journal of Political Economy 105 (1997) 976-1000.

[19] Schmitt-Grohé, Stephanie, and Martín Uribe. "Price Level Determinacy and Monetary Policy under a Balanced-Budget Requirement." Journal of Monetary Economics 45 (2000) 211-246.

[20] Schreft, Stacey L., and Bruce D. Smith. "Money, Banking, and Capital Formation." Journal of Economic Theory 73 (1997) 157-182.

[21] Schreft, Stacey L., and Bruce D. Smith. "The Effects of Open Market Operations in a Model of Intermediation and Growth." Review of Economic Studies 65 (1998) 519-550. 
[22] Taylor, Jon B. "Discretion versus Policy Rules in Practice." Carnegie-Rochester Conference Series on Public Policy 39 (1993) 195-214.

[23] Taylor, Jon B. "The Lack of an Empirical Rationale for a Revival of Discretionary Fiscal Policy." American Economic Review 99 (2009) 550-555.

[24] Woodford, Michael. Interest $\&$ Prices, Princeton University Press, Princeton, New Jersey, 2003. 
Figure 1: Function $\eta(k)$

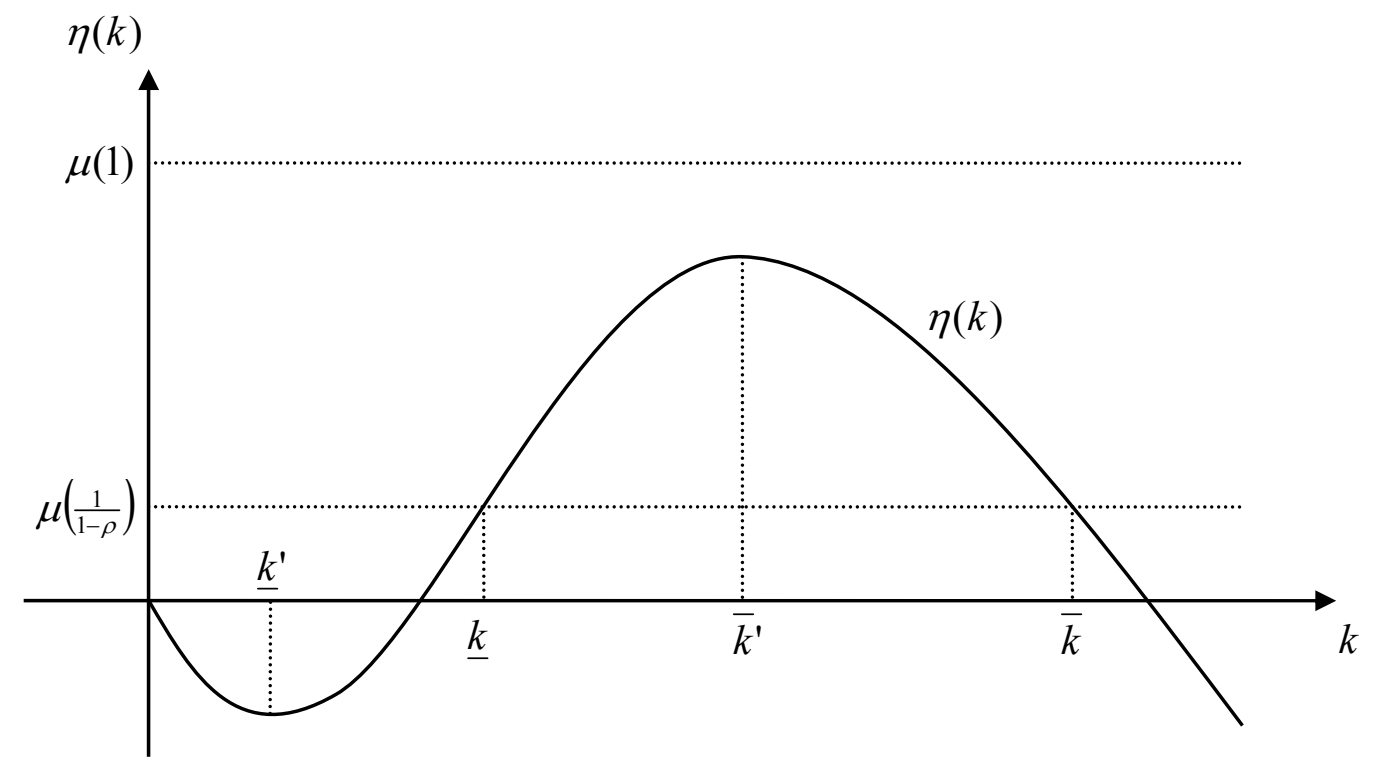

Figure 2: Function $\Omega(k)$

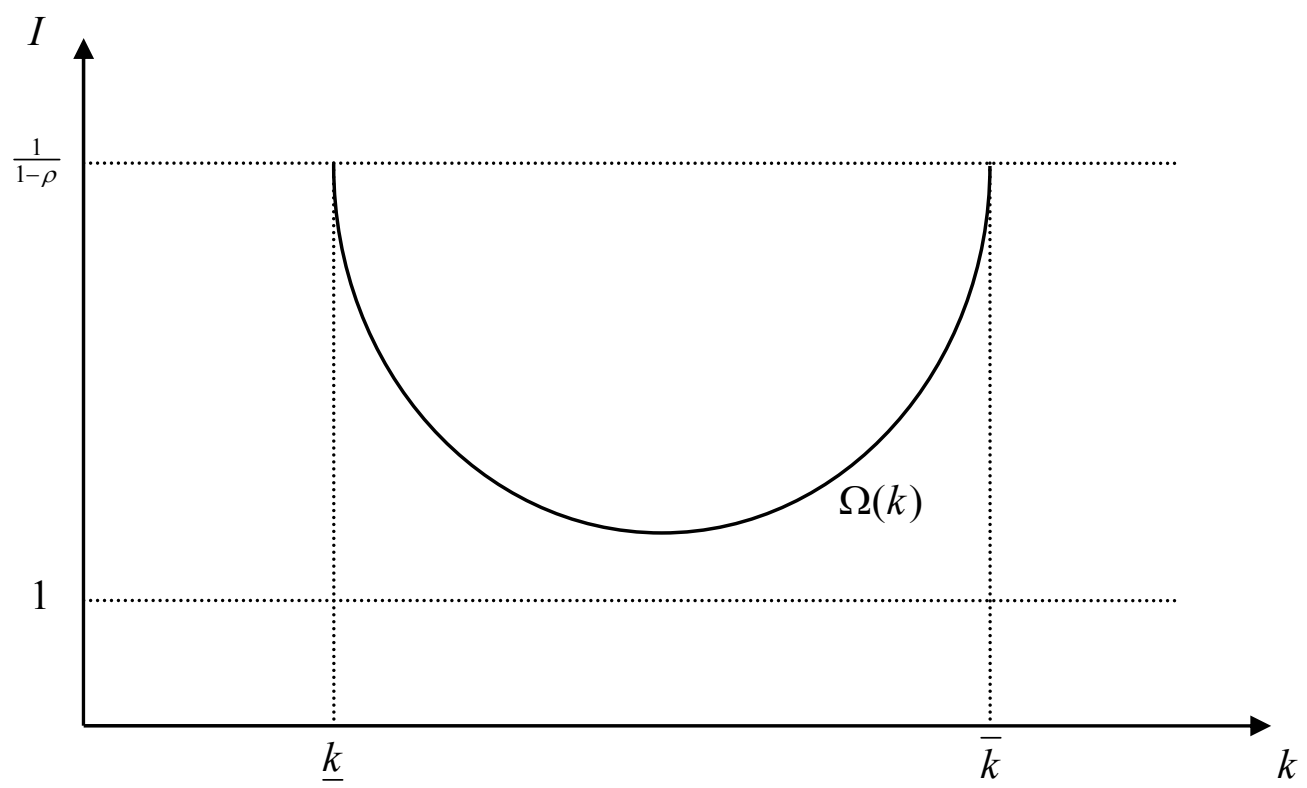


Figure 3: Unique equilibrium

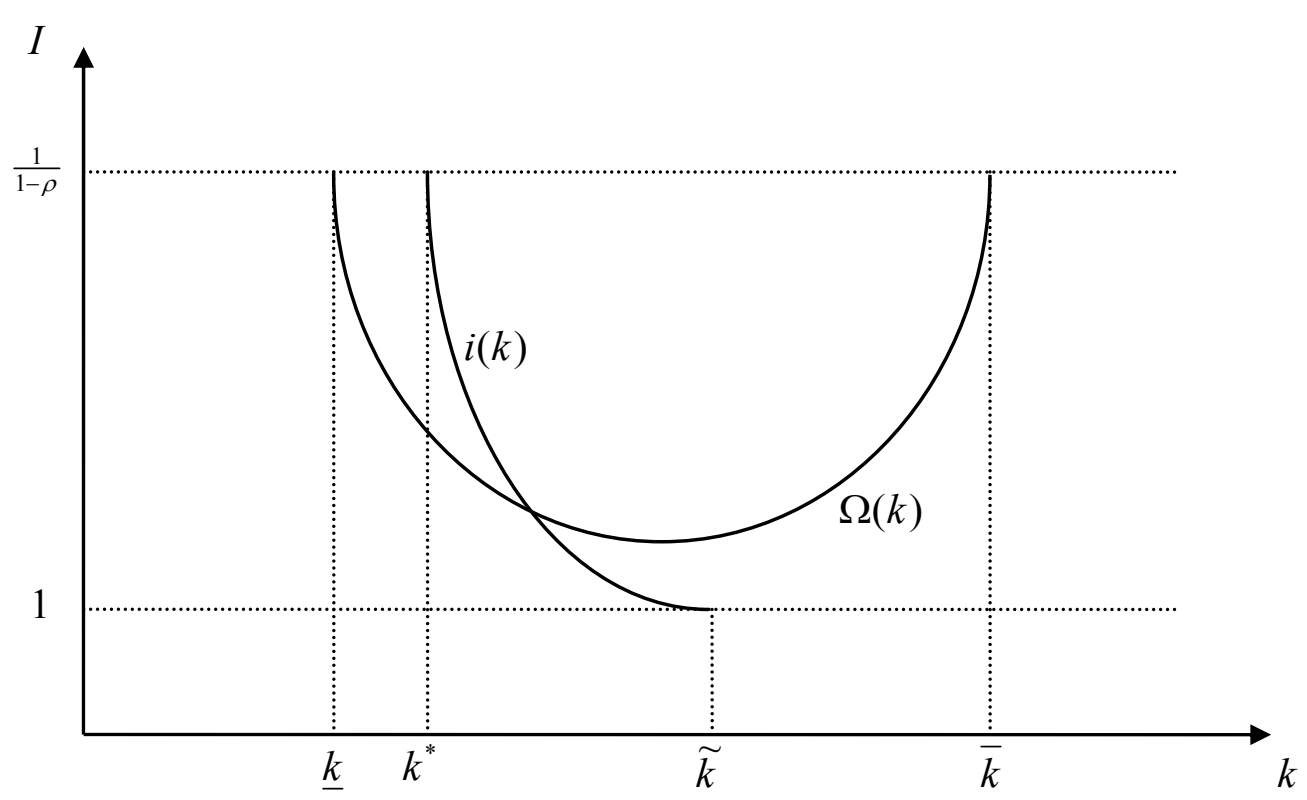

Figure 4: Multiple equilibria under an active monetary policy

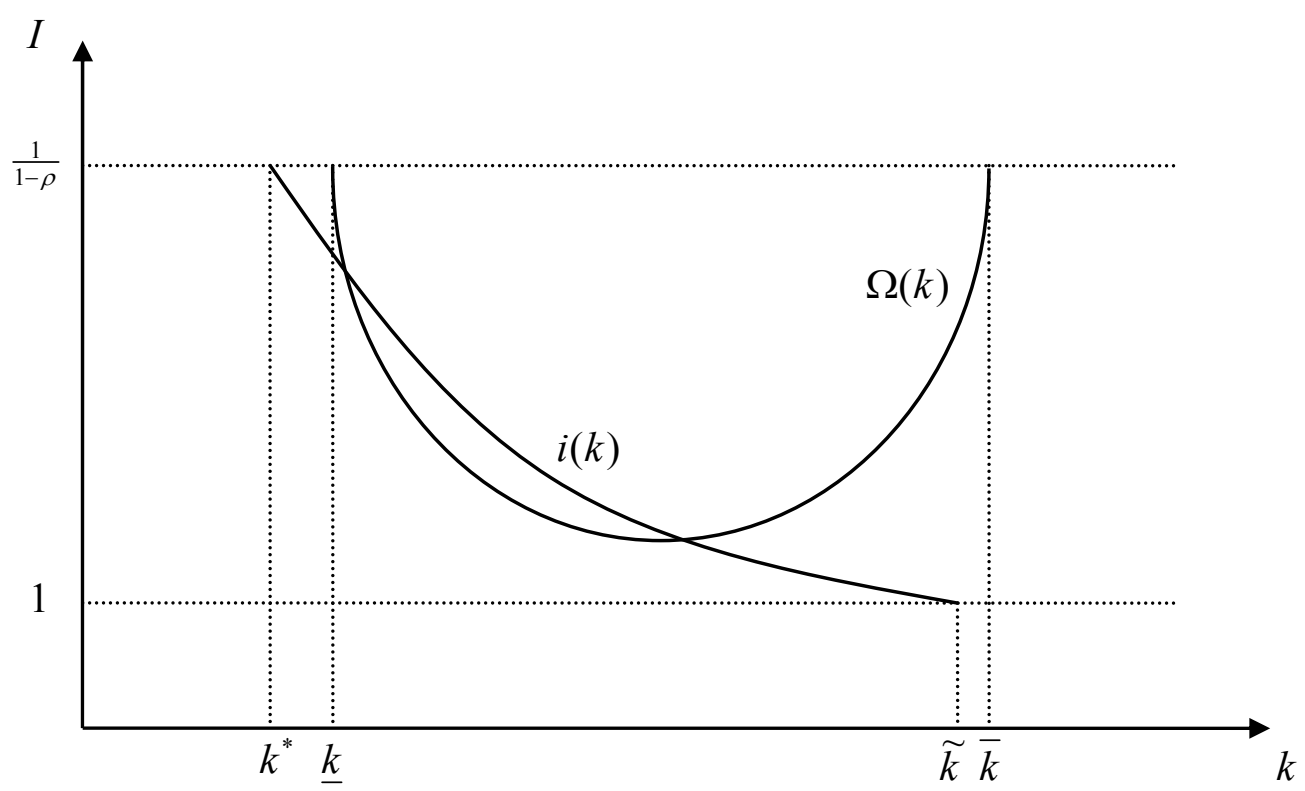


Figure 5: Multiple equilibria under a passive monetary policy

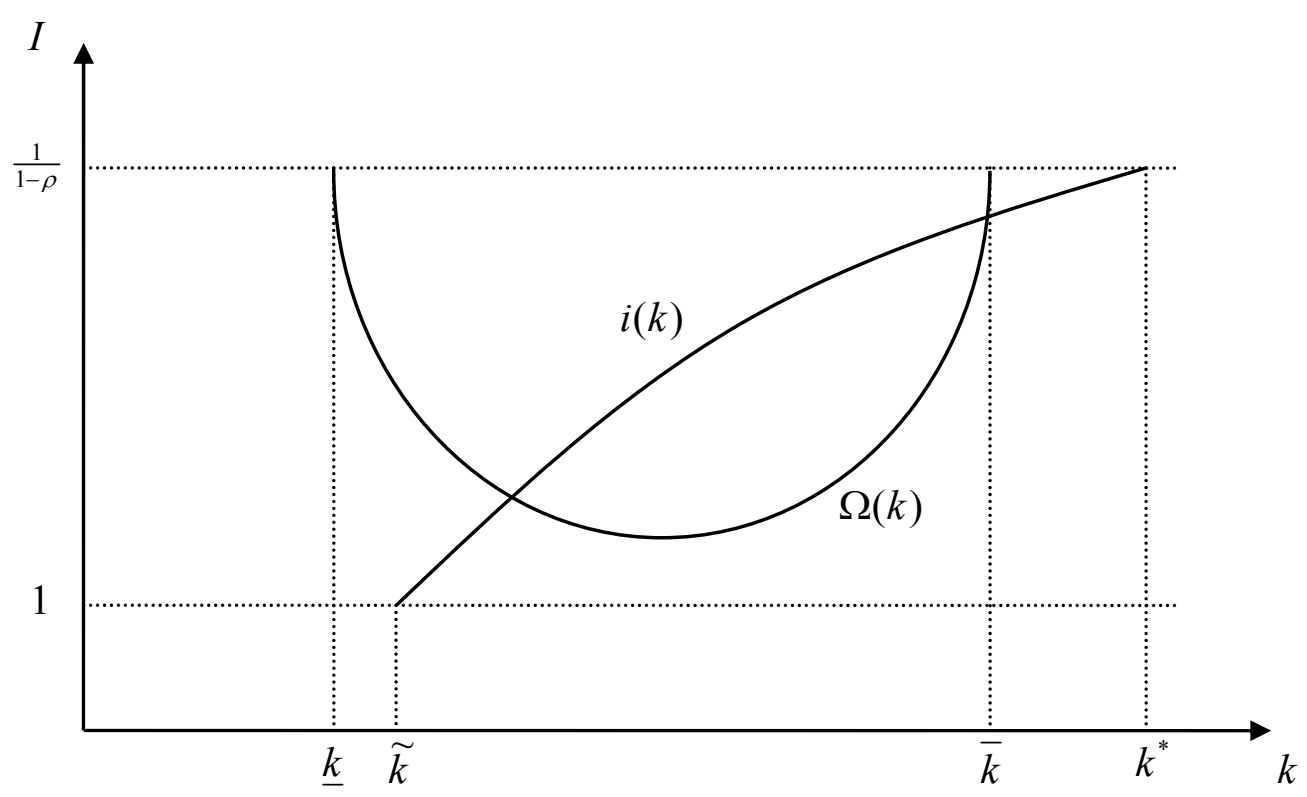

Figure 6: Fiscal policy under unique equilibrium

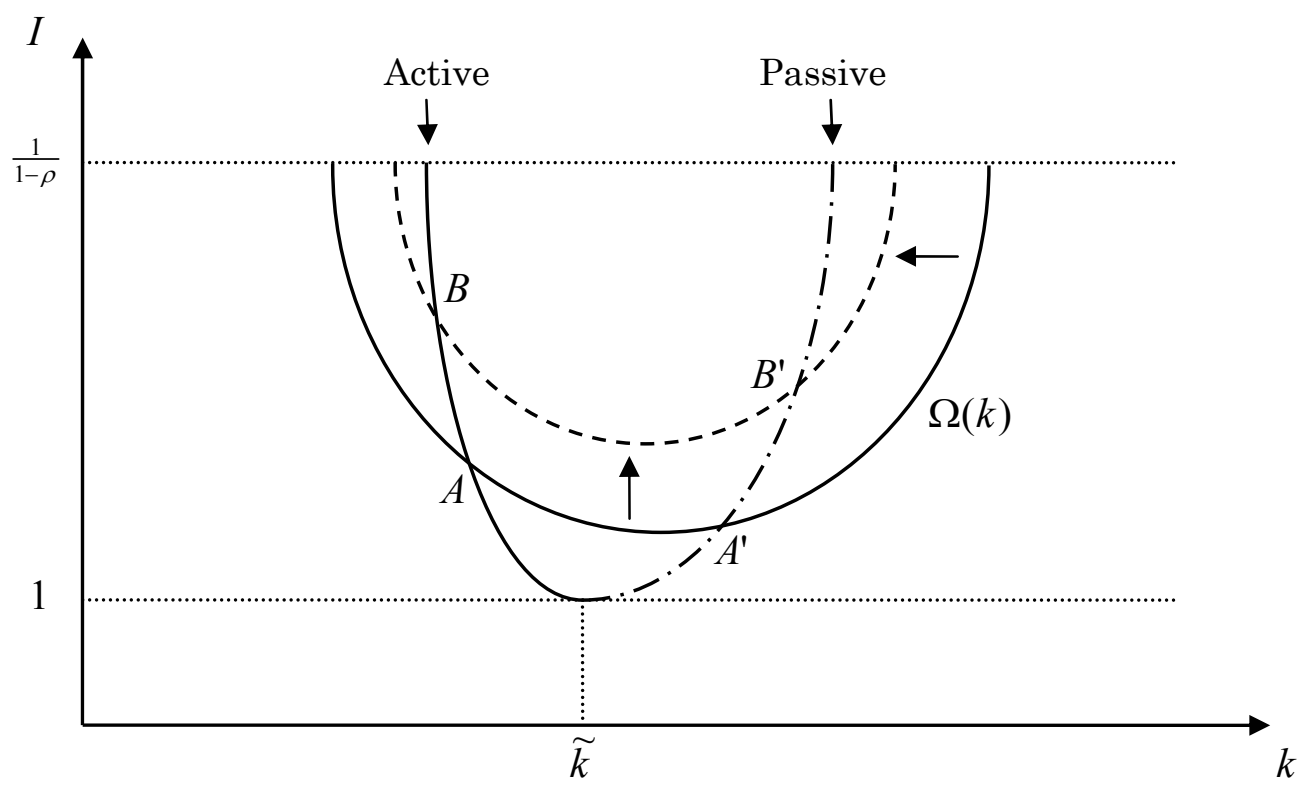


Figure 7: Fiscal policy under multiple equilibria

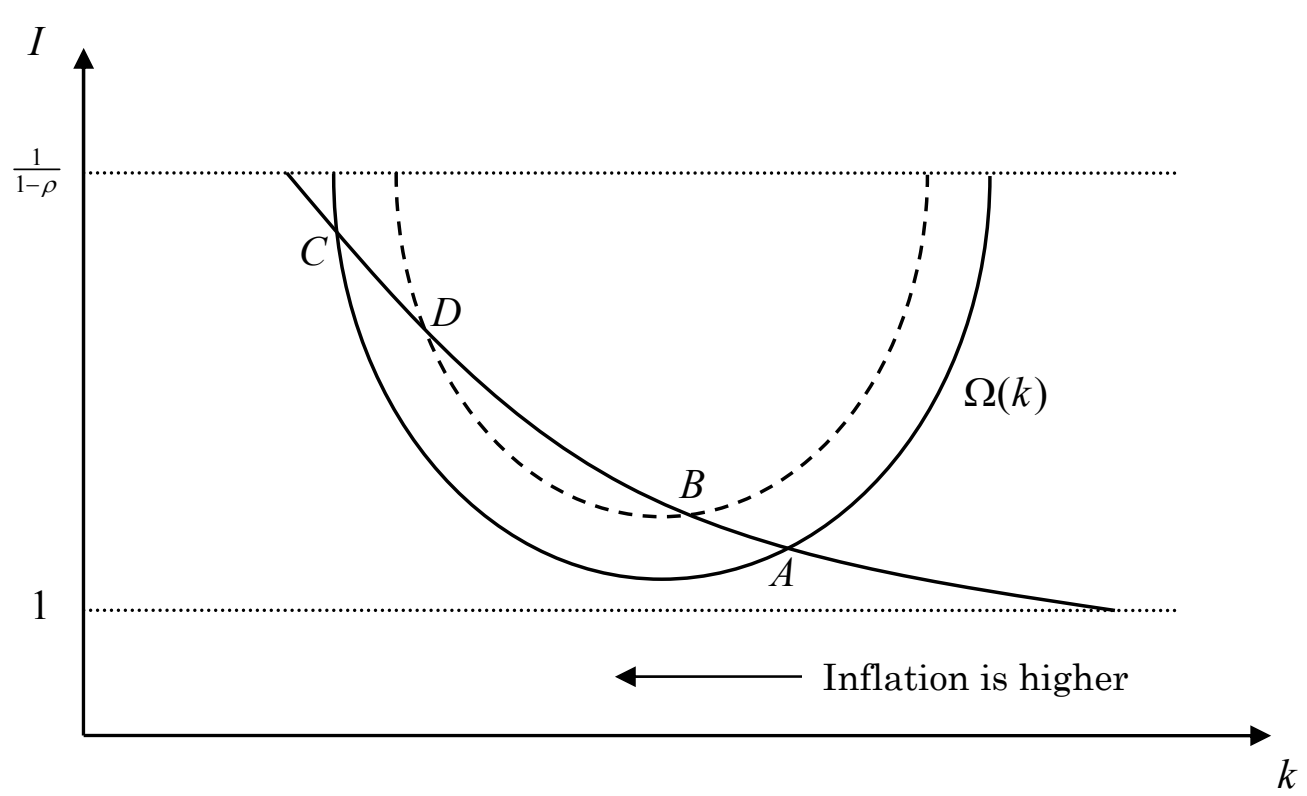

Figure 8: Fiscal policy under multiple equilibria

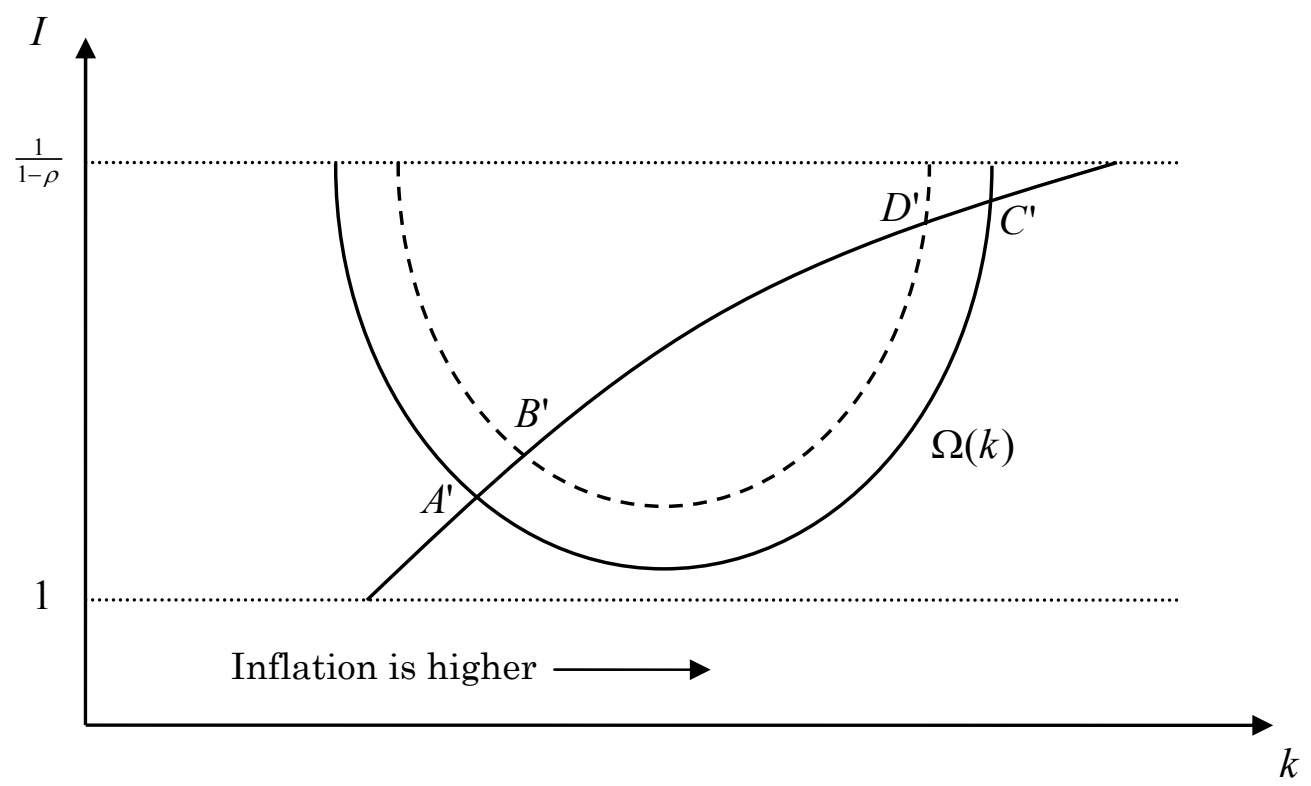


Figure 9: Active monetary policy under elastic money demand

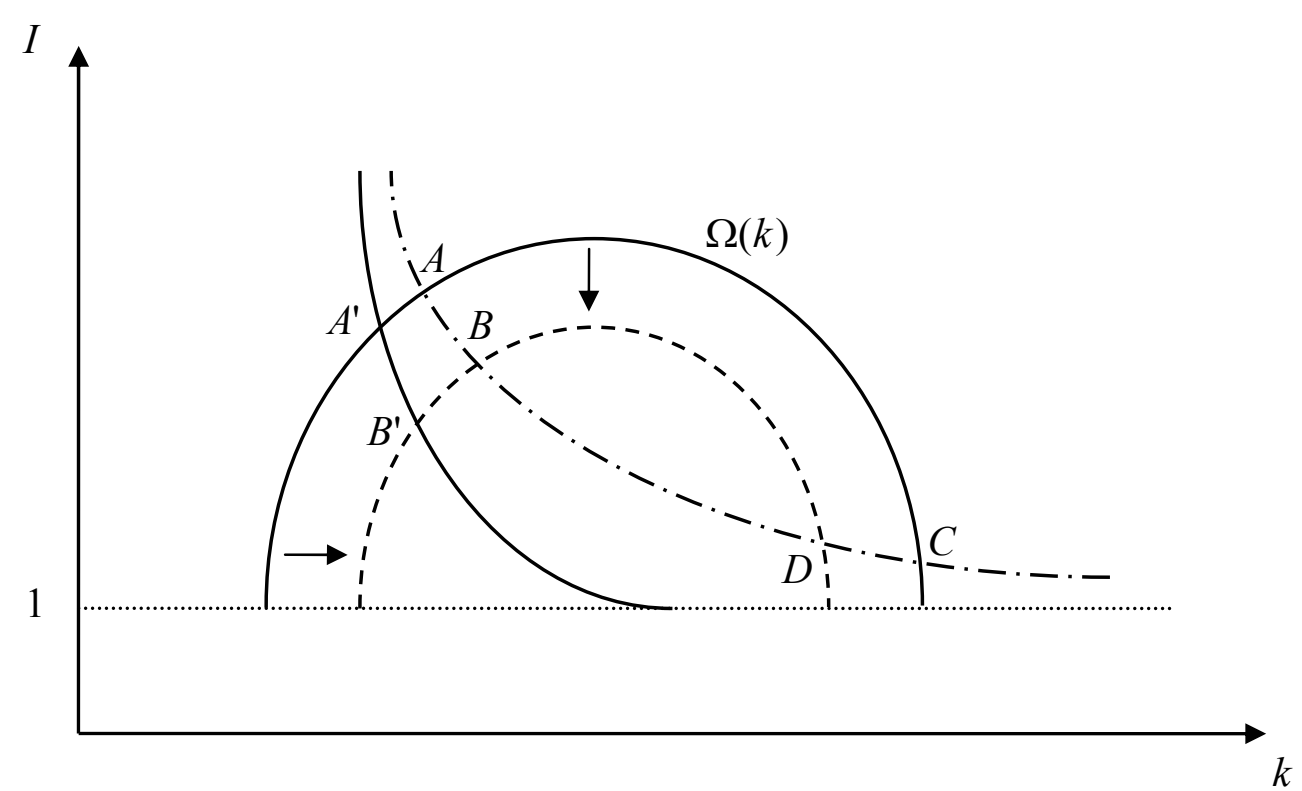

Figure 10: Passive monetary policy under elastic money demand

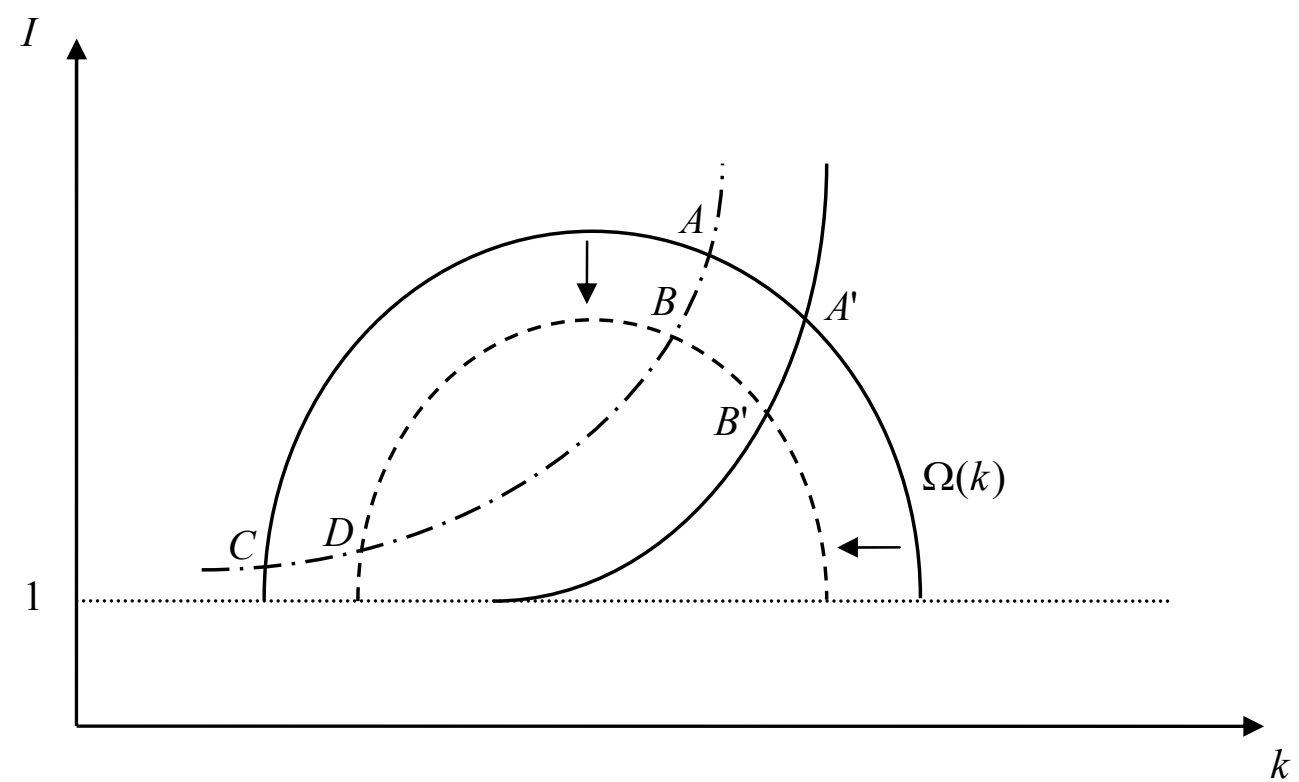

